\title{
Mass Spectrometric Approach Delineating Degradation Mechanism of Synthethic Polymers by Benzoylferrocene
}

\author{
Shuji Kagawa, ${ }^{1}$ Hideya Kawasaki, ${ }^{2}$ and Ryuichi Arakawa ${ }^{* 2}$ \\ ${ }^{1}$ Yokohama Laboratory, Science and Technology Research Center, Inc., Mitsubishi Chemical Group, \\ 1000 Kamoshida-cho, Aoba-ku, Yokohama 227-8502 \\ ${ }^{2}$ Department of Chemistry and Materials Engineering, Kansai University, 3-3-35 Yamate-cho, Suita, Osaka 564-8680
}

(Received October 22, 2009; CL-090944; E-mail: arak@kansai-u.ac.jp)

The degradation effects of benzoylferrocene (BF) on poly(ethylene glycol) (PEG) and poly(methyl methacrylate) (PMMA) were investigated using MALDI-MS. It is supposed that the release of free radicals in solution by BF plays a key role in the decomposition of PEG and PMMA. MALDI-MS combined with examination of the degradation by BF could be applied to the analysis of synthetic polymer structures containing the PEG and PMMA chain.

Matrix-assisted laser desorption/ionization mass spectrometry (MALDI-MS) is one of the most powerful tools that can be utilized for the analysis of synthetic polymers. ${ }^{1-5}$ Typical sample preparation involves mixing the analyte with UV-absorbing organic matrices. Various ferrocene derivatives (e.g., ferrocene, hydroxymethylferrocene, and ferrocenecarboxylic acid) were found to be used for matrices for MALDI-MS; especially benzoylferrocene (BF) revealed an efficient matrix for synthetic polymers. ${ }^{6}$ However, in the case of the ionization of poly(ethylene glycol) (PEG) using a BF matrix, the mixed solution comprising $\mathrm{BF}$ and $\mathrm{PEG}$ was unstable, and the color of the solution turned from light red to brown red over several hours. At the same time, we noticed that degradation of PEG had occurred in the mixed solution. In this paper, the degradation of PEG and poly(methyl methacrylate) (PMMA) by BF was investigated using MALDI-MS to delineate the mechanism of PEG and PMMA degradation.

BF and PEG (average molecular weight: ca. 8000) were purchased from Wako Pure Chemical (Osaka, Japan). PMMA (ca. 15000) was from Aldrich (Tokyo, Japan). BF solution $\left(10 \mathrm{mg} \mathrm{mL}^{-1}\right)$ in acetonitrile, PEG solution $\left(10 \mathrm{mg} \mathrm{mL}^{-1}\right)$ in deionized water and PMMA solution $\left(10 \mathrm{mg} \mathrm{mL}^{-1}\right)$ in acetone/ dichloromethane mixture $(1 / 1, v / v)$ were prepared. For the degradation of PEG, 2-mL BF and 0.5-mL PEG solutions were mixed in a glass bottle. For the degradation of PMMA, 2-mL BF solution, 0.5-mL PMMA solution, and 0.1-mL deionized water were mixed in a glass bottle. For MALDI-MS, sodium trifluoroacetate (NaTFA: $1 \mathrm{mg} \mathrm{mL}^{-1}$ in acetonitrile) as a cationization salt was mixed with the sample solution at a ratio of $1 / 5(\mathrm{v} / \mathrm{v})$ to form sodium ion adducts $\left([\mathrm{M}+\mathrm{Na}]^{+}\right)$just prior to each measurement. Figure 1 shows the chemical structure of $\mathrm{BF}$.

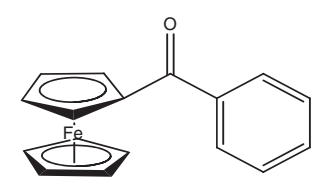

Figure 1. Chemical structure of BF.
The analyte solution $(1 \mu \mathrm{L})$ was spotted onto the MALDI plate using an Eppendorf pipette and then dried under ambient conditions. All measurements were performed on a Voyager-DE STR mass spectrometer (Applied Biosystems, Framingham, MA, USA) equipped with a nitrogen laser source $(\lambda=337 \mathrm{~nm}$ and $3 \mathrm{~ns}$ pulse width); acceleration voltage, $25 \mathrm{kV}$ for the reflector positive ion mode, grid voltage, $65 \%$ and delay extraction time, $250 \mathrm{~ns}$. A mass spectrum was collected by 500 laser shots from each sample spot.

Figure 2 shows MALDI mass spectra $(m / z$ 1000-12000) at different elapsed times $(0,1.5$, and $3 \mathrm{~h})$ after mixing $\mathrm{BF}$ and PEG. Immediately after mixing, $0 \mathrm{~h}$ (a), well-resolved ions with a spacing of $44 \mathrm{Da}$ are detectable around $m / z 8000$. This observation suggests that $\mathrm{BF}$ is an efficient matrix for the ionization of PEG. At an elapsed time of $1.5 \mathrm{~h}$ (b), ions from the degradation appear around $m / z \quad 1000-3000$, while the intensity of ions from undegraded chains around $m / z 8000$ decreases rapidly. These MALDI mass spectra indicate that the degradation of PEG occurred in the mixed solution with BF. At an elapsed time of $3 \mathrm{~h}$ (c), the corresponding mass spectra were almost identical to the spectrum of (b). From the results described above, the degradation of PEG by BF occurred in a few hours.

The end groups of the PEG degradation products were determined from the molecular weight calculated from $\mathrm{m} / \mathrm{z}$ observed as sodium ion adducts. The expanded spectrum $(\mathrm{m} / \mathrm{z}$ 1040-1190) of PEG at an elapsed time of $3 \mathrm{~h}$ (Figure 3) shows nine distinct ion degradation products designated by the symbols $\mathrm{A}, \mathrm{A}^{\prime}, \mathrm{A}^{\prime \prime}, \mathrm{B}, \mathrm{B}^{\prime}, \mathrm{B}^{\prime \prime}, \mathrm{C}, \mathrm{C}^{\prime}$, and $\mathrm{C}^{\prime \prime}$, which were assigned using examples from the analysis of $\mathrm{PEG}$ ultrasonic degradation ${ }^{7}$ (Table 1).

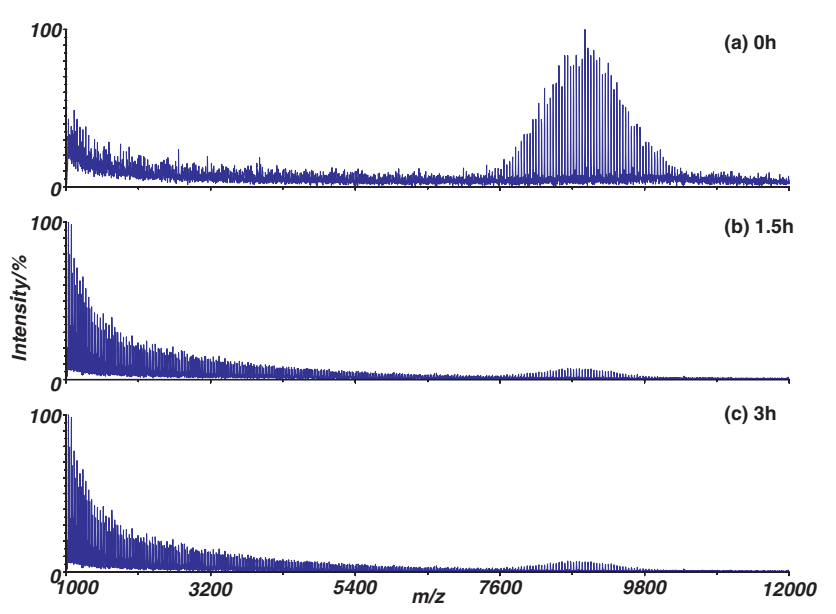

Figure 2. MALDI mass spectra of PEG. Elapsed time after mixing PEG with BF of (a) 0, (b) 1.5, and (c) $3 \mathrm{~h}$. 


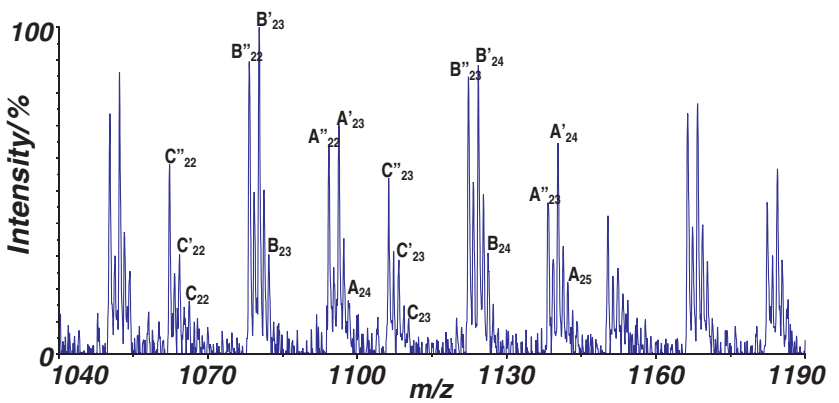

Figure 3. MALDI mass spectrum of PEG after mixing with $\mathrm{BF}$ for $3 \mathrm{~h}$.

Table 1. Structural assignments of the peaks in the MALDIMS spectrum of Figure 3

\begin{tabular}{|c|c|c|c|}
\hline Mass series & Oligomer structures & $n$ & $m / z$ \\
\hline A & $\mathrm{H}-\mathrm{OCH}_{2} \mathrm{CH}_{2}+\mathrm{O}$ & $\begin{array}{l}24 \\
25\end{array}$ & $\begin{array}{l}1097.6 \\
1141.7\end{array}$ \\
\hline$A^{\prime}$ & $\|_{\mathrm{H}-\mathrm{CCH}_{2} \mathrm{fOCH}_{2} \mathrm{CH}_{2} f_{\mathrm{n}} \mathrm{OH}}$ & $\begin{array}{l}23 \\
24\end{array}$ & $\begin{array}{l}1095.6 \\
1139.6\end{array}$ \\
\hline$A^{\prime \prime}$ & $\prod_{\mathrm{H}-\mathrm{CCH}_{2}-\mathrm{OCH}_{2} \mathrm{CH}_{2} \mathrm{f}_{\mathrm{n}} \mathrm{OCH}_{2} \mathrm{C}-\mathrm{H}}^{0}$ & $\begin{array}{l}22 \\
23\end{array}$ & $\begin{array}{l}1093.6 \\
1137.6\end{array}$ \\
\hline B & $\mathrm{CH}_{3} \mathrm{CH}_{2}-\mathrm{OCH}_{2} \mathrm{CH}_{2}-\mathrm{OH}_{\mathrm{n}} \mathrm{OH}$ & $\begin{array}{l}23 \\
24\end{array}$ & $\begin{array}{l}1081.6 \\
1125.6\end{array}$ \\
\hline $\mathrm{B}^{\prime}$ & $\left.\left.\mathrm{H}_{2} \mathrm{C}=\underset{\mathrm{H}}{\mathrm{c}}+\mathrm{OCH}_{2} \mathrm{CH}_{2}\right)_{\mathrm{n}} \mathrm{OH} \quad \mathrm{oCH}_{2} \mathrm{CH}_{2}\right)_{\mathrm{n}}$ & $\begin{array}{l}23 \\
24\end{array}$ & $\begin{array}{l}1079.6 \\
1123.6\end{array}$ \\
\hline $\mathrm{B}^{\prime \prime}$ & 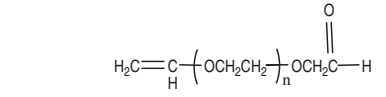 & $\begin{array}{l}22 \\
23\end{array}$ & $\begin{array}{l}1077.6 \\
1121.6\end{array}$ \\
\hline C & $\mathrm{CH}_{3} \mathrm{CH}_{2}-\mathrm{OCH}_{2} \mathrm{CH}_{2}{ }_{-\mathrm{n}} \mathrm{OCH}_{2} \mathrm{CH}_{3}$ & $\begin{array}{l}22 \\
23\end{array}$ & $\begin{array}{l}1065.6 \\
1109.6\end{array}$ \\
\hline$C^{\prime}$ & $\mathrm{H}_{2} \mathrm{C}=\underset{\mathrm{H}}{\mathrm{C}}+\mathrm{OCH}_{2} \mathrm{CH}_{2} \mathrm{~T}_{\mathrm{n}} \mathrm{OCH}_{2} \mathrm{CH}_{3}$ & $\begin{array}{l}22 \\
23\end{array}$ & $\begin{array}{l}1063.6 \\
1107.6\end{array}$ \\
\hline $\mathrm{C}^{\prime \prime}$ & $\mathrm{H}_{2} \mathrm{C}=\underset{\mathrm{H}}{\mathrm{C}}+\mathrm{OCH}_{2} \mathrm{CH}_{2}+{ }_{\mathrm{n}} \mathrm{O}-\underset{\mathrm{H}}{\mathrm{C}}=\mathrm{CH}_{2}$ & $\begin{array}{l}22 \\
23\end{array}$ & $\begin{array}{l}1061.6 \\
1105.6\end{array}$ \\
\hline
\end{tabular}

It was suggested that the degradation pathway of PEG in solution with BF comprises two steps. The first step involves cleavage of the PEG chain by free radicals derived from BF. The second step involves termination of the radical chains with extraction or release of a hydrogen atom to yield the various degradation products (Table 1). Water molecules would facilitate the degradation since addition of water enhanced the effect.

Figure 4 shows MALDI mass spectra at different elapsed times $(0$ and $5 \mathrm{~h})$ after mixing BF and PMMA. Immediately after mixing, $0 \mathrm{~h}$ (a), well-resolved ions with a spacing of $100 \mathrm{Da}$ are detectable. At an elapsed time of $5 \mathrm{~h} \mathrm{(b),} \mathrm{the} \mathrm{intensity} \mathrm{of} \mathrm{ions}$ from the degradation was reduced throughout the entire mass range.

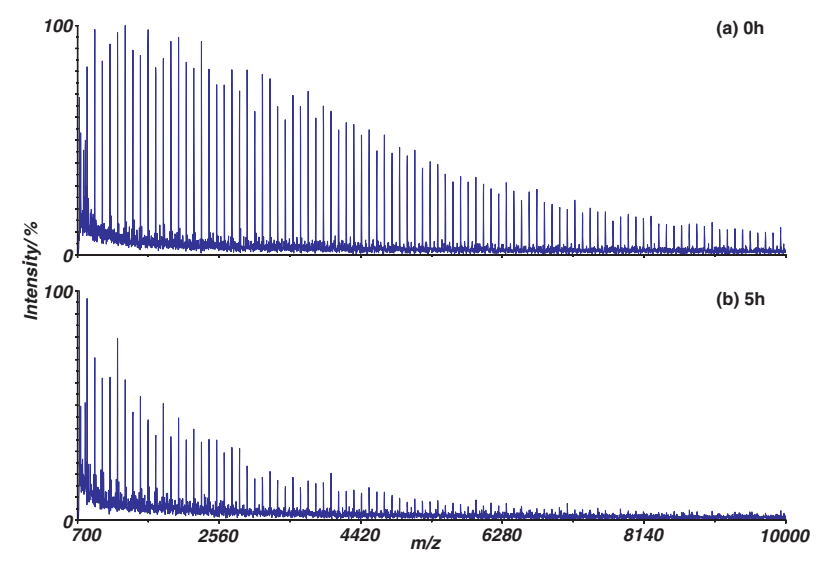

Figure 4. MALDI mass spectra of PMMA. Elapsed time after mixing PMMA with BF of (a) 0 and (b) $5 \mathrm{~h}$.

The end groups of the PMMA degradation products were determined as with the case of PEG, and this confirmed the simple cleavage of the methyl methacrylate (MMA) unit. Consequently, the degradation pathway of PMMA in solution involves cleavage of the MMA unit and subsequent formation only of protonated molecular products. The difference in the degradation between PEG and PMMA is probably due to a weaker $\mathrm{C}-\mathrm{O}$ bonding in $\mathrm{PEG}$ from attack of radical species than $\mathrm{C}-\mathrm{C}$ in PMMA.

Arakawa and co-workers reported on the degradation of PEG and PMMA using an ultrasonic method. ${ }^{7,8}$ The degradation products and pathway of the BF-induced degradation of PEG and PMMA were very similar to those observed in the ultrasonic experiments. Accordingly, it is supposed that the degradation investigated in this study was mediated by free radicals derived from $\mathrm{BF}$.

In this study, we investigated the degradation of PEG and PMMA by BF using MALDI-MS to examine the degradation products and pathways. It was supposed that free radicals released into solution by BF played a key role in the degradation of PEG and PMMA. The use of MALDI-MS combined with examination of the degradation by BF could be applied to the analysis of synthetic polymer structures.

\section{References and Notes}

1 U. Bahr, A. Deppe, M. Karas, F. Hillenkamp, Anal. Chem. 1992, 64, 2866.

2 M. W. Nielen, Mass Spectrom. Rev. 1999, 18, 309.

3 N. Sakurada, T. Fukuo, R. Arakawa, K. Ute, K. Hatada, Rapid Commun. Mass Spectrom. 1998, 12, 1895.

4 R. P. Quirk, R. T. Mathers, C. Wesdemiotis, M. A. Arnould, Macromolecules 2002, 35, 2912.

5 G. Montaudo, F. Samperi, M. S. Montaudo, Prog. Polym. Sci. 2006, 31, 277.

6 S. Kagawa, H. Kawasaki, R. Arakawa, to be published.

7 H. Kawasaki, Y. Takeda, R. Arakawa, Anal. Chem. 2007, 79, 4182.

8 Y. Takeda, H. Kawasaki, T. Watanabe, K. Ute, R. Arakawa, Polym. J. 2008, 40, 682. 